Uluslararası Mühendislik

Cilt/Volume:12 Sayı/Issue:2 Haziran/June 2020

Derleme Makalesi / Review Article

\title{
A Review Study on Assessing the Sustainability of Design and Maintenance of Slab Track Systems for Turkey
}

\author{
Alper Cebeci ${ }^{1}$ \\ ${ }^{1}$ ODTU, İnşaat Mühendisliği Bölümü, Üniversiteler Mah., Dumlupinar Bulv. No:1, 06800 Çankaya/Ankara, TÜRKIYE
}

Kabul / Accepted: 04/02/2020

Çevrimiçi Basım / Published Online: 18/03/2020

Son Versiyon/Final Version: 30/06/2020

\begin{abstract}
Many railway companies around the world offer slab track (ballast-less track) rail products and solutions. In particular, different types of slab track rail systems are implemented in Japan, Europe and North America. The use of these systems provides railway operators with significant advantages in terms of RAMS (Reliability, Availability, Maintainability and Safety) and life cycle cost. In addition, these systems are preferred in railway lines under heavy train traffic, because it significantly shorten maintenance duration. The biggest disadvantage of ballast-less railway lines is that the initial application cost is $30 \%$ to $50 \%$ higher than ballast railway applications. In recent years, manufacturers of these systems have introduced innovations that reduce both maintenance and life cycle costs. When these innovations are added to the existing advantages in the design phase in tunnels (reduction of the height) and bridges (reducing dead loads), the applicability of slab track systems increase even more. In addition, maintenance and repair activities have to be carried out in limited time in heavily used railway lines such as high-speed railway lines, which causes slab track systems to be preferred. By the construction of high Speed rail lines in Turkey, the passengers and freight rail transport has gained importance. Increasing rail traffic, maintenance-repair costs and limited maintenance duration have led to the need to step changes on the conventional ballasted railway lines. Within the scope of this study, the slab track systems, which have already utilized in the world are examined and the sustainability of these systems that can be applied in Turkish railways is examined in terms of design and maintenance.
\end{abstract}

\section{Key Words}

"Slab Track, Sustainability, Turkey" 


\section{Introduction}

In order to enhance competition with road and airline transports, along with other efforts, railway undertakings are increasing their speed as well as upgrading their system safer, more reliable and more available. In this regard, high-speed lines (HSL) has become crucial. Railway infrastructure companies must construct better railway lines to provide safety, reliability and maximum availability in HST services. The densely populated areas in the world are mostly formed of different level layers, which are often alluvial in nature, and of which subsoil has geotechnical characteristics that range from weak to strong. Building railway structures on the weak ground would require a substantial improvement of the bearing capacity.

High-speed trains have begun to be adopted by countries due to its quality, safety and speed. Many different slab track types are used in different countries around the world. Especially in Japan, Germany and North America, these systems have been used as effectively since the 1970s. Conventional ballasted track has been used in many parts of the world since the beginning of railway technology, but a significant competition has emerged with the introduction of slab track after 1972. According to Bilow et al. (n.d.), Japanese have used the slab track systems more than thirty years in the railway systems. They acknowledge that current construction costs of slab tracks are $30 \%$ to $50 \%$ higher than the construction costs of standard ballasted tracks. However, the maintenance costs of slab tracks are $40 \%$ of the maintenance costs of ballasted tracks. (Bilow \& Randich, 2000)

Slab track suppliers have achieved significant developments in these systems. At the beginning, slab track systems were used solely for reducing the life cycle cost and for providing more reliable track operation. Nowadays, they are also used for reducing the tunnel height, track height and for increasing the availability of the systems. While slab track systems are implemented, countries consider different ground stability features as well as economic conditions. For instance, some of them are struggling with extreme weather conditions whereas others have to cope with seismic behavior of the ground. This situation also affects the competition among slab track producers.

According to the UIC regulation, a line is described as a high-speed line, if the designated train operation speed on the line is above $250 \mathrm{~km} / \mathrm{h}$. Conventional lines which are upgraded for trains to operate between the speeds of $200-220 \mathrm{~km} / \mathrm{h}$ can also be considered as high-speed line. The technical requirements such as reliability and availability indicate that track type selection is one of the most significant issues that should be taken into the consideration while constructing a railway line. Since the first construction of the railways, the ballasted track principles have not changed significantly despite the innovations that have taken place in other areas of the railways.

In this study, the application methods, advantages and disadvantages of the suitability of slab track systems are discussed. In addition, the most widely used slab track types in the world have been examined in detail. As it is known, Slab track systems are used very limited in Turkish railways. These applications are very new. Therefore, it is premature to see the results of existing applications in terms of Reliability and Maintainability. This paper will try to contribute by sharing the literature and the results obtained through its use in the world. Given the nearly 50 years of slab track experience in some countries, the type of slab track to be selected becomes very important.

In the scope of this study, the studies conducted in the past will be presented first. Then the selected slab track types will be explained in detail. Section 3 examines slab track systems in terms of Reliability, Availability, Maintainability and Safety (RAMS), which play an important role in railway applications. Finally, the results will be explained in the Conclusion.

The significance of slab track systems for the railway infrastructure has been the subject of many researches. Groundbreaking study on the comparison of slab track and ballasted track is one of the well-known among these researches. (Esveld, Modern Railway Track 2nd Edition, 2001) He has analyzed the slab track types and its material features, which are currently in use around the world. Moreover, he has allocated a chapter in his book for the requirements of special parts of the slab track systems such as track resilient layer as well as the use of slab tracks in tunnel and bridges. Furthermore, he referred the maintenance statistics of the slab track in his study inclusively. Drawing upon Esveld's (2001) and, Lichtberger (2005) studies on the track system components; on the other hand, he has mainly focused on the slab track systems. At the beginning of his study, he has provided details by presenting the requirements of the slab track in terms of subsoil, sound protection, transition areas, signaling and energy supply. After that, he has compared slab track and ballasted track with their advantages and drawbacks. Then, he has discussed the economic efficiency and cost of slab track systems. He has provided a comprehensive table to show the differences among the slab track types.

Profillidis (2006) has examined the selection of track types for railways and provided some information about the slab track systems and their usage. (Profillidis , 2006) In his study, has briefly compared slab track with ballasted track. Railway tracks provide a structure that guide the train in certain position. The track on a railway, which is also known as the permanent way, can be defined as a structure that includes the rails, fasteners, sleepers, ballast (or slab) and subgrade. The track systems comprises of two main structures. The first one is the superstructure layer, which contains rails, sleepers, ballast and the sub-ballast. This layer supports the train and distributes its load into the subgrade. The second one is subgrade layer, which consists of formation layer and base. This layer allows transfer of trainloads from the superstructure to the ground. Although the ballasted track systems have been traditionally utilized in the railways, they may alternatively replace by the concrete slab track systems. Slab track systems have been successfully used particularly in high-speed lines, urban tramways and metro systems. 


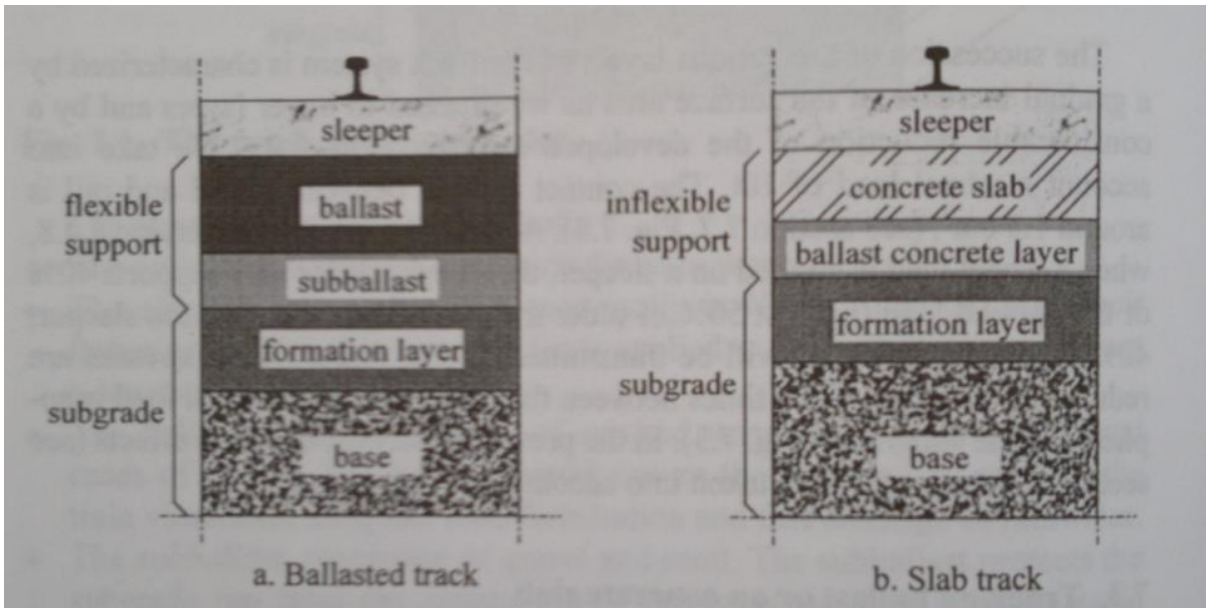

Figure 1. Differences between Ballast-Less Track and Ballasted Track (Profillidis , 2006)

According to Lier (2002) have produced important results for the study on the slab track types as well as their advantages and drawbacks. Furthermore, there are two important studies in the field; the first one is introduced and discussed the features of quality management for production of Ballast-less track (Slab Track) by Japanese Companies, which can act as a reference for the Concrete sector in Taiwan. (Shiau, Huang, Wang, \& Lu, 2008)The second one is conducted by (Hussein \& Hunt, 2009). They have presented a new method for production modelling of the floating slab tracks with discontinuous concrete in the railway tunnels. This study is very beneficial study for the literature and it helps to understand floating slab track behavior and their features. (Esveld , 2003)

Bilow \& Randich, (2000) have investigated the slab track systems in detail, which are commonly used in the world. Various types of slab track systems have been utilized around the world. The Canadian Pacific Railway (CPR) built a test line, whose patent name is PACT-TRACK, near Rogers Pass in British Columbia to simulate and investigate the slab tracks. Since the slab tracks were successfully tested, the railway in the McDonald Tunnel built by using slab tracks. Both the test and tunnel sections built by using slab tracks have performed well. Concrete is placed by using a specialized slipform paver (paving machine). Concrete is fed in front of the paver using a conveyor system. After the concrete dries, the continuous welded rail is laid on the concrete layer. Finally, thick rubber pad and the rail are clipped to inserts embedded in the slab.

Slab tracks are extensively used for the construction of high-speed lines in Japanese National Railways (JNR). The high-speed railways require a certain alignment to increase passenger comfort. JNR has used slab track systems on the Shinkansen high-speed train network as well as on some of the narrow gauge lines since 1980. Also, they have considered some of the issues that are direct selection criteria for the slab track construction. The construction cost shall not be $30 \%$ more than ballasted track construction cost. Slab track should show equivalent behavior with ballasted track in terms of damped sound and degree of resilience. Furthermore, it shall allow for small changes in both vertical and lateral directions to minimize the deformations of the subgrade (Bilow \& Randich, 2000).

The maintenance cost of slab track is found to be lower than the maintenance cost of ballasted railway track on the Shinkansen high-speed lines. Slab track maintenance cost ranges from $18 \%$ to $33 \%$ of the maintenance cost that required for ballasted track (Shiau, Huang, Wang, \& Lu, 2008). On the other hand, the construction cost of ballast-less track is $30 \%$ higher than the cost required for the ballasted track. The difference in these costs can be balanced in 8 to 12 years with maintenance cost. Another crucial example for slab track application done in the Eurotunnel under the English Channel, where the designated train speed is $200 \mathrm{~km} / \mathrm{h}$. In this project, the slab track was named as Low Vibration Track (LVT) which was developed by Sonne-Ville International Corporation. The LVT has also been used in the Los Angeles County Metropolitan Transportation Authority, Metro Link - St. Louis and Dallas Area Rapid Transit systems in the United States, and in an other countries. (Bilow \& Randich, 2000) The Embedded Rail System (ERS) has been utilized since 1970s in the Netherlands. This system consists of called Corkelast, which consists of cork and polyurethane mixture which may provide continuous support for rails on the slab track. This system is extensively used for the light railway transportation in Europe and is also implemented on the bridges. Recently, in the south of the Netherlands, a $3 \mathrm{~km}$ length of the ERS concrete slab track has been built and placed on the subgrade.

Slab track usage has been undergone development in Germany for many years. In 1996, German Railway began to operate a test track in Karlsruhe, which consists of seven new types of ballast-less tracks. One of the famous type of slab track type ise Rheda compact design, which is one of the well-known designs that developed during the 1970s in Germany. This design utilizes a top down method of construction. After the rail is positioned on the line and subgrade, concrete is placed below and around the ties, partially embedding the ties. Approximately $147 \mathrm{~km}$ of slab tracks have been constructed along the new $219 \mathrm{~km}$ Cologne-Rhine high-speed line. The saving at maintenance cost has offset the higher initial construction costs of the slab tracks. Also, the greater availability of the tracks due to less downtime for track maintenance (Bilow \& Randich, 2000). 


\section{Development of Slab Track Structures: Case studies on Selected Types}

Slab track is used in both light rail systems and intercity railway lines. It might be also utilized in railway corridors, on which passenger trains share the railway track with freight trains operations. In slab track, the load distributing element "ballast" is replaced by another material which has a stable position, such as concrete or asphalt. The plastic deformation of these materials is very low in regular circumstances. The elasticity of the structure has to be provided by inserting elastic elements under the rail or the sleeper, as the concrete or asphalt layer is very stiff. In general, a slab track system provides reduction in the structure height and weight, lower maintenance costs and, hence, higher availability and increased service life.

The general problem, which arise from conventional or ballasted track, is the slow deterioration in the ballast layer under the railway traffic conditions. As stated earlier, the ballast layer consists of granular materials, which can be damaged while it is under the influence of friction and turn into fines (smaller particles). These fines may cause drainage problems. For this reason, the ballast layer requires regular maintenance during the operation. This maintenance reduces the life of the ballast as well as having an impact on reliability, availability, maintainability and safety (RAMS).

Maintenance work, such as tamping, ballast cleaning and track lining brings $20 \%$ to $30 \%$ extra cost for the ballasted track. The slab track systems reduce most of this maintenance costs. Additionally, it should be kept in mind that the drag force becomes more and more important factor with the increase of train speeds. High-speed trains cause flying ballast phenomena, which is difficult to cope with it. Therefore, extra precautions must be taken while operating very high-speed trains on the ballasted tracks or slab tracks should be utilized for the construction of very high-speed railway lines.

The first recorded slab track usage is dated back to 1899, when American Southern Railroad built a concrete slab under the section of an existing railway track to stabilize it on the poor soil (Bilow \& Randich, 2000). Furthermore, slab track systems started to be widely utilized on the light railway systems in USA and Canada. In these countries, slab track is extensively utilized on mixed traffic corridors. In this type of sections, light rail systems share the pavement with automobiles and buses.

Substructure requirements become more significant with the improvement of slab track systems for the high-speed railways. The limited track geometry adjustments constrain to design sensitive substructure for the ground settlements. Especially the embankments should be stabilized for the settlement of track. Soft subgrade can be strengthened with the compacted soil. An alternative and sophisticated solution is the usage of mixture, which includes cement instead of compacted soil. In other words, slab track can be utilized on the poor bearing grounds.

Ballasted track requires embankments with maximum of 2 centimeters settlement for over 10 meters track length (Lichtberger ,2011). These requirements are very low for the slab track. The small settlement can be controlled by fastening from +26 millimeters to -4 millimeters for the slab track (Michas, 2012). In addition, the substructure of the ballasted track has to be secured by earthworks, excavating until the 0.5 meters depth below the frost protect layer. However, the sub-structure of the slab track needs to be stabilized to a depth of at least $2.5 \mathrm{~m}$ below the bearing plate. In terms of the earthworks, these requirements have led to higher construction cost for slab track compared to ballasted track (Esveld, Modern Railway Track 2nd Edition, 2001). The regular composition of layers consists of two important sub-layers: improved ground and the protection layer.

These earthworks for the ground-improvement can be achieved by dynamic compaction and/or mix-in-place methods. In some soils, the weak ground layers are replaced with mixture of the better layers. The geotechnical requirements for the embankment can be provided by proctor densities, which are designated between $98 \%$ and $95 \%$, depending on the age of the track.

The first application of ballast less tracks (slab tracks) in the railways was the installation of slab tracks in tunnels. The low construction height of the slab tracks provides best conditions for using them in the tunnels. In case of enlargements of the tunnel gauge within the existing tunnels, the small construction height is a major advantage for land use.

The reinforcement of the tunnels becomes extremely important with the expansion of railway networks. Both passenger and freight trains use many tunnels, which requires better tolerances for the structure. The electrification of some railway networks often necessitates the lowering of the track heights in the tunnels and this lowering can be done by slab track systems rather than ballasted ones. There are also other issues such as alignment design and vertical adjustability, which should be considered in the tunnel construction.

Total construction height of tunnels is limited due to cost and geological issues. Tunnels formations are extremely important in order to ensure that whether the selected slab track system is suitable. Tunnel formations can show different behaviors under loads, such as extreme settlement, which must be considered during track type selection. The concrete layer with 30 centimeters thickness in the grade may be reduced to 15 centimeters for the use in tunnels. Inside the tunnel, some specific requirements, such as drainage and emergency access, can also be met by this adjustment. The ground properties in terms of rock/soil have to be appropriate for the installation of slab track. All structural types of ballast less track used at different grade can be applied in tunnels.(Sonne Ville,2019)

Bridges and viaducts provide a solid foundation for the slab track, but it is short and discontinuous. In addition, external factors such as temperature and vibration can affect bridges. These external factors can cause longitudinal movements of the bridgestructure. Thus, the slab track structure as well as the bridge structure are affected. Bridge structures provide the required settlementfree base for slab tracks. Longitudinal deformation of the bridge structure is caused by temperature variation. Longitudinal dilatation 
has to absorb the energy without trigging high longitudinal rail stresses. In case of long bridges, i.e. those over 25 meters, the track has to be fixed to the bridge structure.

In continuous welded rail (CWR) tracks on the bridges, considerable longitudinal rail forces and relative displacements may develop due to the external factors such as temperature variations, acceleration and braking. These stresses are caused by the interaction between the bridge deck and the track system; therefore, the interaction have to be limited as it causes additional stresses to the rail stresses generated on the normal track section.

The cuttings and embankments are the crucial part of the railway lines construction. The local settlement on the embankments should be reduced so that influence from the slab track structure is not seen. The earthwork construction should provide high stability and low settlement. The subgrade has to be compacted in order to avoid long-term settlement of track. If the requirements cannot be fulfilled by standard compaction methods, subgrade treatment or methods for acceleration of settlement must be utilized. Moreover, the existing soil has to be replaced if its bearing capacity is insufficient. Soft, cohesive or organic soil in the subgrade should be replaced up to a depth of 4 meters minimum below the surface of rail. The influences of measures during construction, such as lowering the groundwater level, should also be considered.

The cuttings have the similar strict regulations as the embankments. The required arrangement of layers and compaction needs to be provided 3 meters below the surface of rail. The subgrade needs to be durable and provide a suitable bearing capacity combined with small settlement behavior. Soft, cohesive or organic soil must be replaced or other treatment has to be implemented in order to limit settlement.

If the track system consists of both ballasted and slab tracks, the superstructure transitions are needed on the railway line. Furthermore, transitions also occur between substructures such as embankments, bridges and tunnels. Transitions need to be done smoothly between the different track structures. As it is seen from the figure 2, the high stiffness of the slab track (ballast-less track) needs to have step change through the lower stiffness of the ballasted track. The level of transition or transition zone length might be changed depending on the sub-structure stiffness.

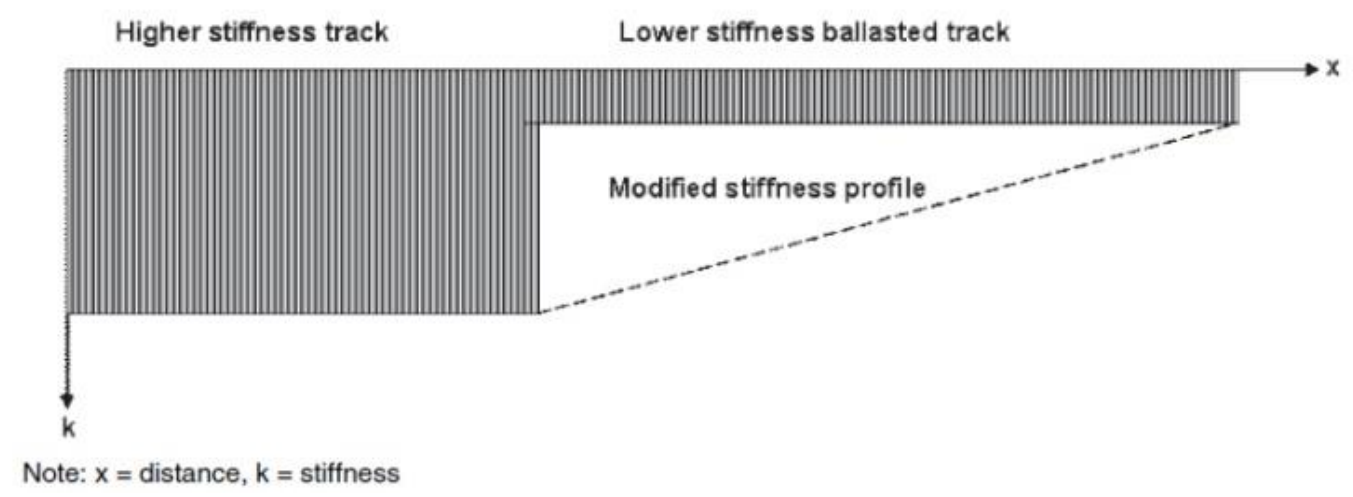

Figure 2. Transition zone between Ballast-Less Track and Ballasted Track (Michas, 2012)

In these transition zones, temperature and other environmental issues become important as they intensely affect the track structures. Problems can also arise due to different construction height of tracks and there are number of methods available for solving these problems. However, the author emphasizes one method that is widely known and economic. In case of transitions between track structures, the rails must be directly fastened to sleepers. The stiffness, flexibility and settlement of tracks are very significant elements for the transitions.

There are several other requirements that should be considered in the slab track systems such as frost protective layers, sound protections, signaling systems and electro-technical specifications. The frost protective layer serves compensation for the stiffness of the other subsoil layers, as it has to lead surface water away rapidly. For this reason, it should have $1 * 10-5 \mathrm{~m} / \mathrm{s}$ permeability. (Lichtberger, 2011)

\subsection{Sleepers or Blocks Embedded in Concrete}

\section{Rheda 2000}

These systems have been used since its first installation in 1970 and it has been under continuous development since then. In its first design, mono-block sleepers are embedded in the reinforced concrete. The new Rheda 2000 slab track system has produced because of the ongoing improvements in the well-known German Rheda system. Additionaly, this system has also been designed for commuter traffic application, which is known as Rheda City. The track framework can be adjusted in lateral and longitudinal directions. The settlement is very important for this type of slab track systems. The primary development goal for the Rheda system is to improve the monolithic quality, which will lead to optimized design and uniform architecture. With this design, geometrically supporting points can stabilize the rails in their required position. Supporting points produced with high quality concrete provide a strain-resistant bond, which is a stable point between the rail fastening system and the concrete tracklayer. (Lier, 1999) 


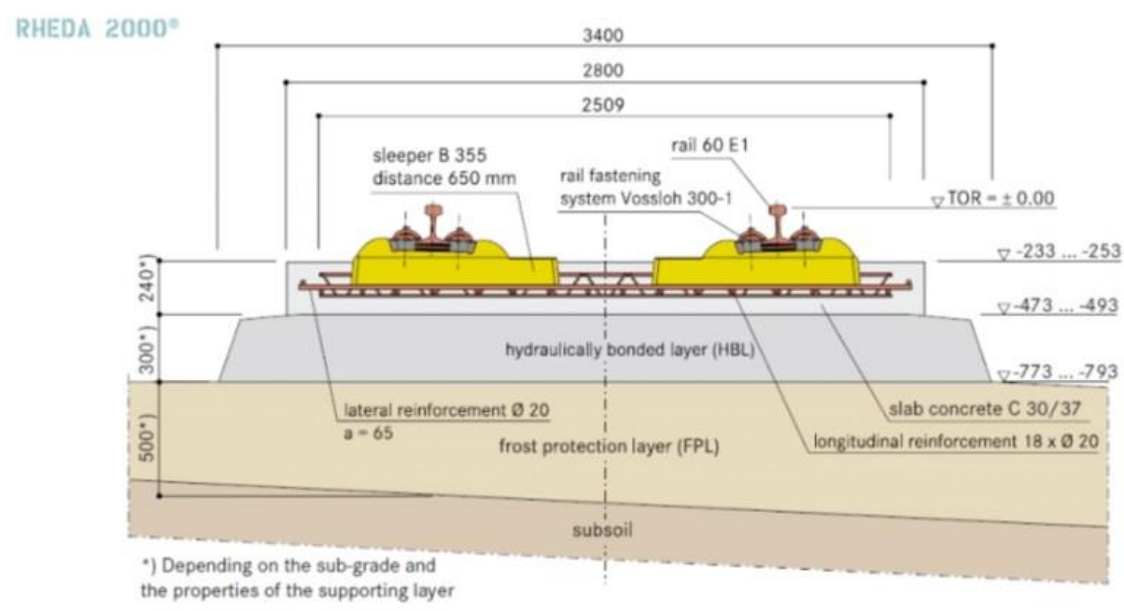

Figure 3. General layout for Rheda 2000 Slab Track system (Rail One, 2020)

Rheda systems may show different behaviors in its various versions. However, Rheda 2000 system has eliminated all the previous designs. The main characteristic of the system is the cast concrete tracklayer, which consists of rail and framework for the sleepers. This technique can tolerate the unavoidable effects of track components. In addition, the rail fastening system allows adjusting the long-term differential settlements of the substructure. The reason behind the cost effectiveness in planning is that this system design must fit a variety of track situations in practice. Therefore, solutions have been developed for infrastructure of track systems consist of earthworks, bridges and tunnels. (Esveld, 2001)

\section{Zublin System}

This system might be consist of concrete twin block or monobloc sleepers, which are embedded in the monolithic concrete plate. The designers of the Zublin system have focused on finding a highly affordable construction method back in 1974. (Matias, 2019) Zublin system is a 24 centimeters thick and 2.8 meters wide load-bearing slab with integrated twin-block sleepers. Two individual reinforced concrete sleeper heads are connected to form a twin-block sleeper. The reinforcing bars provide not only accurate geometry during the installation but also give the sleepers additional anchorage in the concrete. The geometry of the sleepers is designed for the Vossloh AG's rail fastenings (Vossloh, 2019). The rail fasteners are pre-mounted on the twin-block sleepers prior to the installation. Designers endeavor to achieve a sufficient level of mechanization combined with low labor cost and efficient production of track.

After the improvement of soil, the concrete roadbed is constructed upon the soil with the monolithic concrete slab, which is produced by slipform paver. When the paver has laid the concrete plate, a machine that follows the paver pushes up the sleepers onto the concrete by means of vibration. (Railway Technology, 2019) The Zublin system can produce 150-200 meters of tracks in 8 hours a day. The construction steps of the Zublin system is provided below:

- Preparation and construction of the sub-base and base course;

- Reinforcing, concreting and compacting of the concrete bearing slab without interference of the sleepers;

- Fixing the sleepers by compacting with pre-mounted fasteners;

- Installation of rails;

- Implementation of the surface of the slab by hand;

- Waiting for the concrete hardness;

- Disconnection of the frames from the sleepers.

\subsection{Structure with Asphalt-Concrete Roadbed}

Asphalt layer was started to be used in railways, similar to that commonly used in highway construction. Asphalt-concrete bed layer is used especially in slab track structures that require rigid sub-structure. This development led to provide higher quality and longer lasting track and support structures to accommodate the high amount of growth in rail traffic volumes, revenue ton-miles, axle loadings, and tonnages being experienced throughout the world. (Rose \& Souleyrette, 2015)

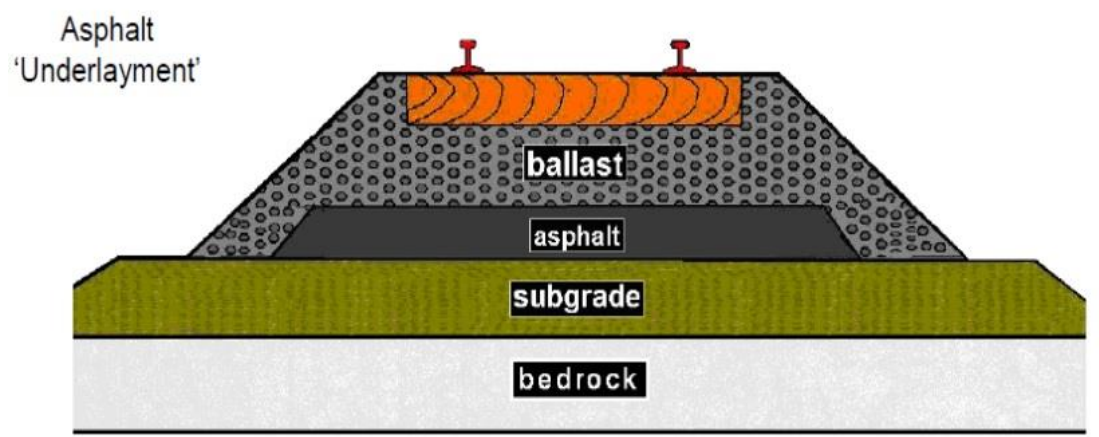

Figure 4. Ballast-less track bed containing asphalt and sub-ballast layers (Rose \& Souleyrette, 2015) 
In this ballast less structure, sleepers are placed on the top of an asphalt-concrete roadbed layer which is made by ordinary paving devices. With this method, it might be reach the level accuracy of +/- 2 millimeters and cant deficiency of up to 180 millimeters. Thus, the asphalt provides a stiff and smooth base for the sleepers. (Railway Technology, 2019)

Another possibility of placing the concrete plate on the top of an asphalt-concrete layer. Since asphalt does not require hardening. This might be subjected to loading/unloading immediately after the cooling. (Esveld, Modern Railway Track 2nd Edition, 2001)

\subsection{Prefabricated Slabs}

Prefabrication of track components can increase the slab track quality. Prefabricated slabs are utilized in several railway networks around the world. These systems bring several advantages in design and implementation of the high-speed line projects. Since the mechanization usage reached to higher levels, these systems require less labor force and decrease the risk of failure. Prefabricated systems are known as reparable and innovation friendly. (Gailiene \& Lasurinavicius, 2017)

Prefabricated concrete plates with direct rail fastening have utilized on the Japanese Shinkansen high-speed line and on the Italian system. The utilization of prefabricated elements eliminates the usage of wet concrete during construction. Many urban rail system and interregional high-speed rail system have compatible prefabricated concrete plates applied on the particular railway section. This railway system is utilized in convenient areas with respect to noise and vibration. This system might cause increase height for the track and the cost of installation.

\section{Shinkansen Slab Track}

Many people agree that Japan was the birthplace of high-speed rail systems. Development work on the Shinkansen high-speed rail network started at the end of 1950s, and the first high-speed line was opened between Tokyo and Osaka in 1964. As of today, five high-speed lines are operational and the sixth one is under construction. South Korea is currently building a high-speed line to link its capital, Seoul, with the port of Pusan. As in Japan, South Korean high-speed line will also include both ballasted and ballastless tracks. The construction of ballastless track will be based on the Japanese Shinkansen slab track system.

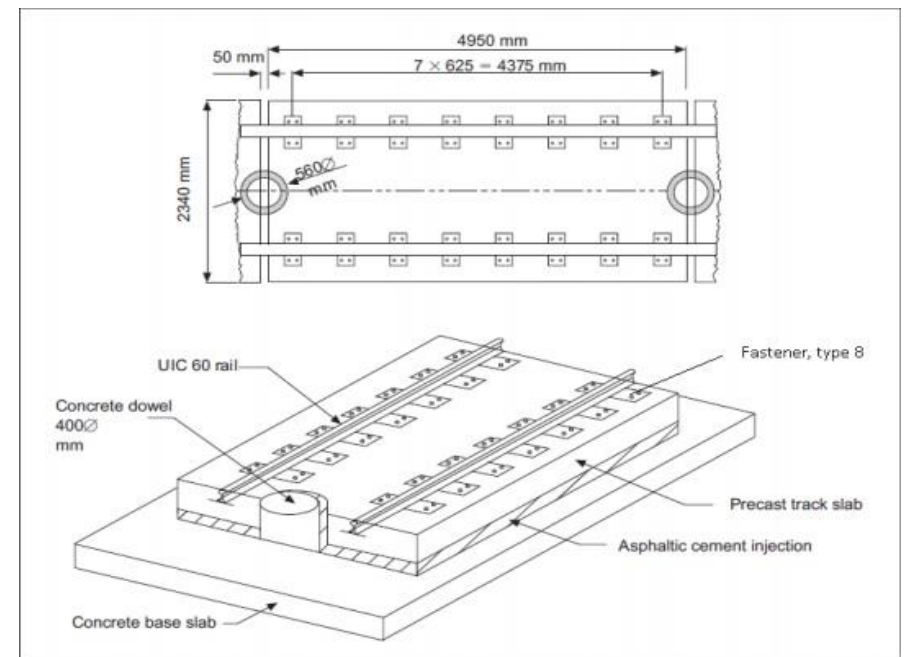

Figure 5. General Layout of Shinkansen Slab Track (Esveld, Modern Railway Track 2nd Edition, 2001)

The rails, which are welded in the depots and are 200 meters long, are loaded on the trolleys which utilize temporarily laid rails which has $1435 \mathrm{~mm}$ gauge. These temporarily rails are used by motor car to follow the slabs as workers are putting cementemulsified asphalt mortar (CA mortar) under slabs in the neighboring line. Slabs are transported to the construction site by rails, which have $3000 \mathrm{~mm}$ gauge. The CA mortar is transferred from the moving plate running on rails with $1435 \mathrm{~mm}$ gauge onto the neighboring line. This moving plant fabricates CA mortar at the construction site by mixing liquid asphalt, cement and sand. This process, rails are put on the concrete plates and connected with normal fasteners. (Esveld, 2001)

\section{Bögl Slab Track}

The first installation of this type of track was at Karslfeld, Germany, in 1977. The purpose of producing Bögl slab track is to provide a long-endurance, maintenance-free operation. This track brings many advantages to the high-speed lines with highest track availability.

The Bögl slab track system is very similar to Shinkansen slab track systems and might be utilized for cutting/embankments, concrete structures such as bridge, viaducts, tunnels etc. The first modification of this system was done by applying the long railway bridge, which was designed for a high-speed line section between Beijing - Tianjin railway line in China, which is almost 116 kilometers long. The 12 kilometers of this slab structure is built on the soil. Each slab has a length of 31.5 meters. (Esveld \& Markine, 2019) The main difference of Bögl from the Shinkansen is that slabs are made of B55 steel fiber reinforced concrete and its measurements are 20 centimeters thick, 6.45 meters long and either 2.55 or 2.80 meters wide. The slabs are pre-stressed in lateral direction and traditional reinforcement is applied in longitudinal direction. Spindles integrated in the slabs to might give a chance to provide an adjustment of the slab system. (Esveld, 2001) 


\subsection{Monolithic Slabs and Civil Structures}

The slab track system consist of rail and direct rail fastening to the concrete plate developed since 1970s. In this type of slabs, the direct rail fastening systems are bolted straight onto the concrete or steel slabs. The continuous monolithic slabs can be installed without sleepers specifically on the bridges or viaducts. In this process, the direct fixation system might be used (Vossloh, Type of Track,2019). This system might be adjusted by approximately $50 \mathrm{~mm}$ in vertical and $46 \mathrm{~mm}$ in lateral direction. The main application areas of this structure are weak and soft layers zones. The minimum requirements for the substructure can be lowered and costs can be saved for ground improvements in certain situations. (Esveld \& Markine, 2019)

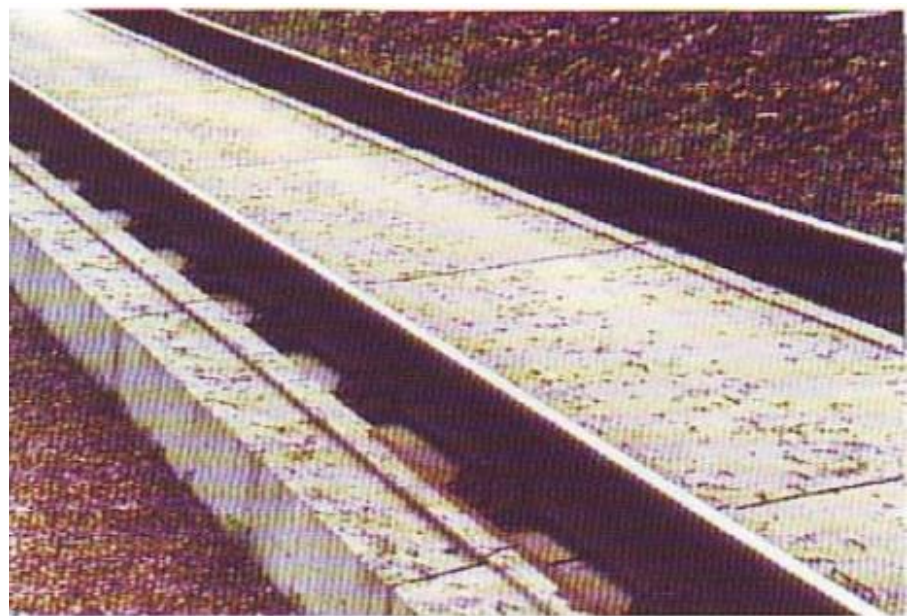

Figure 6. An example of a monolithic slab track design with direct rail fastenings (Esveld, Modern Railway Track 2nd Edition, 2001)

This method of slab track construction provides a continuous stiff and rigid slab, which consist of supported elastic beam. These type structures can also be applied on soils that have a great risk of local settlement on the subgrade.

\subsection{Embedded Rail Slab Track}

Embedded Rail Structure (ERS), which consists of cork and polyurethane with elastic materials surrounding the rail except for its head, provides continuous support for the rail. The main characteristic of this slab track is that rail is embedded underneath the concrete. There is no need for additional material to secure the track gauge under the operational conditions. In the construction process, the continuous support of the rail is provided by elastic materials. The rail is fixed in the U-steel frame and is adjusted by means of top and down methods. Furthermore, the continuous concrete slab is made to allow free settlement on the soil.



Figure 7. An example of an Embedded Rail Slab Track (Michas, 2012)

The ERS slab track systems, which provides elastic continuous support for the rail, have following five advantages: absorbing of dynamic forces, reduction of noise production, increase in life span of the rails, reduction of maintenance and providing free settlement. The construction height might be decreased for level crossings, so that ERS can provide a smooth surface for rail crossings. In 1976, in Netherlands, an ERS pilot track was constructed for the train speeds up to $160 \mathrm{~km} / \mathrm{h}$. Test results were very positive for the beginning. Another pilot was constructed in October 1999 with the dimensions of 3 kilometers length, 0.6 meters height and 2.5 meters width. This process concluded by decreased the $5 \mathrm{~dB}$ noises. Furthermore, ERS system provides $60 \%$ reduction for the UIC54 elastic design to secure the rails. (Esveld, 2001)

Deck Track

These systems can be a solution for reducing the settlement issues and the life-cycle costs (LCC) of both high-speed and heavy freight lines. Deck track is a new type of ballast-less track developed to use on relatively soft soils. The rails can be directly applied as an embedded rail or with direct fastening. The concrete deck can be considered as a hollow tube weighing the same mass as that of the removed soil. This track provides less vibration and less settlement as a result of the structure weight. (AASHTO, 1993) 
After five years of the testing process, the settlements and the quality of the structure have been evaluated. The concrete structure and embedded track system did not show any sign of deterioration. The widest cracks in the concrete carrier those at locations at the beginning and end of a day's production (casting joints) that are less than 0.1 millimeters wide, which is largely acceptable (Esveld, 2001)

\section{Assessing the Sustainability of Design and Maintenance of Slab Track Systems: Case Study for Turkey}

Nowadays, there has been ongoing debates over the fundamental track type selection. Both ballasted and ballastless (slab) track systems have several advantages and disadvantages. Table 1 below illustrates the comparison of ballasted track and slab track systems on the similar areas in Germany. The maximum speed in NBS Frankfurt-Cologne high-speed lines is $300 \mathrm{~km} / \mathrm{h}$ whereas in Würzbuerg is $250 \mathrm{~km} / \mathrm{h}$.

Table 1. Slab track versus ballasted track (Bilow \& Randich, 2000)

\begin{tabular}{lcc}
\hline \multicolumn{1}{c}{ Parameter } & NBS Frankfurt-Cologne (Slab Track) & Würzbuerg (Ballasted Track) \\
\hline Max. Gradient & $40 / 100$ & $20 / 100$ \\
Min. Curve radius & $3350 \mathrm{~m}$ & $7000 \mathrm{~mm}$ \\
Max. Cant & $170 \mathrm{~mm}$ & $65 \mathrm{~mm}$ \\
Proportion of Bridges & $9 \%$ & $3 \%$ \\
Proportion of Tunnels & $37 \%$ & $21.5 \%$
\end{tabular}

It indicates that the maximum gradient can be obtained by slab track system and the system can reach minimum curve radius by $3350 \mathrm{~m}$. By increasing the cant, more comfortable ride and higher speed in the curves can be provided. The slab track systems have great benefits for the structures. One of the primarily goals of the author of this paper is to prove that utilization of slab track brings advantages in terms of economy, technology and safety. For this reason, several factors will be taken into account in order to determine the best system in terms of track type selection.

As is mentioned before, ballasted track systems have been developed for a long time, and are still being used on the important highspeed lines such as TGV tracks in France. The ballasted tracks are proven technology since the construction of first railway line. They bring important advantages in terms of cost, labour skills, materials and machinery. They also provide good elasticity and noise damping.

The type of structure to be chosen depends not only on the expected axle loads and speeds, but also on the required service life, the type and amount of maintenance, local conditions and availability of basic materials. The relation between initial cost and maintenance cost is very important to make a correct evaluation during the selection of track type.

The disadvantages for ballasted track should be considered advantageous for the slab track systems. Slab track manufacturers began to develop a competitive edge thanks to these drawbacks. At speed of $300 \mathrm{~km} / \mathrm{h}$, the small ballast grains may lift from the permanent way and may damage the rail as well as the wheels of the trains. The permeability of the contamination can reduce the subgrade structure strength and complicate the ballast cleaning works. Heavy and high track structures require stronger constructions for bridges and viaducts. The rate of maintenance intensity is very high and brings extra burden to the construction cost. In the long term, the life cycle cost becomes crucial due to operational issues.

While designing the future of a railway line, which is part of a railway network with increasing traffic density, factors like life cycle cost, construction time, availability and durability play vital roles. In such a busy railway line, it becomes extremely difficult to complete maintenance and renewal works during the night shift or three to four hours in a day. These operational conditions increase the need for low maintenance track systems.

The slab track provides sufficient productivity by modifying track geometry and decreasing the track maintenance cost for highspeed railway lines. (Esveld \& Markine, 2019) The developed countries such as France, Germany, Japan, Spain and so forth, have started to play significant role in high-speed railway development. However, not all of them utilize slab track. This section analyses high-speed railway systems, which are related to slab track. The slab track advantages can be listed as follows:

- Requires less maintenance or is a maintenance-free structure. For example, Rheda systems require $10 \%$ maintenance of the ballasted track (Esveld \& Markine, 2019)

- Provides higher service life to compare with ballasted track (Esveld, 2001)

- Significantly reduces the dynamic stress on the subgrade. It might be important for unstable areas (Lichtberger, 2011)

- Allows higher value of cant and cant deficiency that permit small horizontal radii on passenger only high-speed lines where trains are relatively short and light;

- Provides higher availability with lower possessions progress (Lichtberger, 2011)

- Provides hard surface for the drainage instead of a crumbled away ballast layer (Lichtberger, 2011) 
- Permits emergency and maintenance machines access;

- Provides better ride quality for the passenger and driver;

- Reduces the track structure height; it thus brings several advantages for the tunnel height. The construction of the tunnels is very expensive, and the reduction of the tunnel height brings economic advantages approximately at $£ 1 \mathrm{M}$ reduction at cost by decreasing 0.1 meter diameter (Esveld, 2001);

- Ballast particles can cause serious damage for the train wheel or rails as a result of churning high-speed impacts (Lichtberger, 2011)

- Provides a cleanable track inside stations;

- The slab track systems reduce the track systems weight. It brings serious advantages for the bridges;

- The slab track systems allow the use of effective and economic braking systems, such as eddy-current braking;

- Apart from these advantages, each slab track design can have a special benefit, such as reduction of noise and vibration with the floating tack systems and so forth.

- Besides, of these advantages slab track systems have some drawbacks, which should be considered in the construction progress. The general drawbacks of the slab track systems can be summarized as follows:

- The higher capital expenditure is one of the drawbacks. Even the politicians and commercial consideration often support lower initial cost during the design process;

- There is not sufficient test data to assess the rate of the deterioration of the slab tracks;

- The rail pad replacement and the application of preventative grindings problem have not been solved yet;

- The ballasted track provides lower carbon footprint and re-usable recovered materials;

- Besides of these general drawbacks, the specific slab track designs may have special disadvantages. Some of them have not improved the life cycle cost and other technical requirements, up to date yet.

Requirements for the slab track systems are changeable depending on the country because of specific needs concerning the superstructure and substructure. In addition, each systems show different behavior, especially in different areas, such as tunnels, embankments and bridges. However, some areas such as noise and vibration sensitive zones require detailed work in the slab track construction. During the construction of very high-speed line, dynamic forces such as braking or accelerating of VHST trains need to be considered.

Ballasted track systems do not allow easy access in case of emergency. Therefore, slab track systems must require easy access for rescue services. In this section, requirements of slab track systems are dealt with in different areas.

Turkish State Railways (TCDD) have been using ballasted track systems for about hundred years. After the government's comprehensive innovation, the high-speed trains have gained more significance for both small and big cities of Turkey. TCDD has started to build high-speed lines back in 2003. In this regard, the first line was constructed between Ankara and Eskisehir, which is the important section of Istanbul to Ankara high-speed line.

In the existing HSL projects such as Ankara-Konya and Ankara-Istanbul, the ballasted track systems have been utilized. When the long-term benefits of the track type are considered, preference of the ballasted track systems is arguable. TCDD wants to increase its networks capacity and reduce the headway of trains. For this reason, managers should consider RAMS (Reliability, Availability, Maintainability and Safety) process for the network.

Reliability engineering is dealing with ability of a system or a component to perform its required functions under stated conditions for a specified period. Under operational conditions, railway tracks should be reliable. Especially for the busy networks, reliability becomes a key factor. Unreliable track systems can cause great delays and harm the entire operation process. The ballasted track systems are still causing important train delays in Turkey. For instance, sometimes, conventional ballasted lines are completely closed for the maintenance. Slab track systems present more reliable systems than conventional ballasted tracks do, because it requires less maintenance facilities.

Availability is the time period in which the system is functioning. This is often described as a mission capable rate. Mathematically, this can be calculated with unavailability. For the railway lines operation, availability is very important and it is also related to its maintenance process. The slab track systems have more availability than ballasted track with its maintenance facilities. Furthermore, the slab track systems can present more availability in case of an emergency such as earthquakes with its easy access and rescue features.

Maintainability is a part of the lifecycle for all products in railway. Maintenance time and cost can increase the products maintainability. Slab track systems require less maintenance than the conventional ballasted track. The maintenance time can be reduced using prefabricated products and if whole product life is considered, maintenance costs will be less than ballasted track. Furthermore, in case of an accident, railway tracks should provide easy access and they should be easily changeable when they are damaged. Safety is the last pillar of the RAMS process that is a vital for all transportation systems. It is necessary to ensure safety for all components in railway systems. The railway tracks can be the cause of accidents, which may result loss of people's lives and properties. Safer systems always increase the desirability of the components or products. It is general fact that both systems provide nearly the same safety facilities for the high-speed lines. 


\section{Conclusion}

Selection of the track type is an argumentative issue for the railway organizations. It becomes extremely challenge to conduct railway track maintenance and rehabilitation work with high-level traffic intensity. In this context, ballasted track concepts have lost their attractiveness in comparison with slab track systems. Utilization of slab track can bring several advantages in terms of construction, such as tunnel or bridge. The life cycle cost, construction time, availability and durability play crucial roles in the design of railway lines (AASHTO, 1993). In this regard, ballastless track concepts introduce good opportunities.

Certain railways such as those of Germany (DB), France (SNCF) and Japan (JR) have developed high-speed ballast-less track. Especially, in Germany, railways authorities have made a decision to construct some of the sections of high-speed lines by using ballast-less track in order to reduce high maintenance cost and to have reliable tracks for avoiding serious problem in their busy networks. However, France still utilizes ballasted track systems for its high-speed lines. Because, the French railway company, RFF, considers the labor skills and utilize the existing machines of the ballasted track systems.

There are number of factors that play crucial roles in calculating the capital expenditure for particular track frames such as construction cost, maintenance cost, and so on. Building costs of slab tracks are much higher, and it can be from $50 \%$ to $75 \%$ higher than the building cost of ballasted tracks. However, operational experience shows that, particularly in tunnels and bridges, the maintenance costs are less than the maintenance costs of ballasted track. Slab track systems reduce the maintenance time and cost in the tunnels. Smaller construction depth and drainage opportunities are also strong advantages for preferring slab track systems. Slab track systems can provide well-improved track geometry with greater lateral stability. However, slab track systems have several disadvantages along with their benefits. Substantially, higher initial construction cost is one of the most significant drawbacks. Furthermore, rigid structure of the slab track allows only limited improvements for future usages. Adaptations to new conditions, such as changes in track geometry, can be difficult to perform and very expensive. However, some of the slab track products can reduce the initial construction cost of the system, such as embedded slab tracks. Moreover, floating slab track systems have been introduced to reduce transmission and propagation of vibration and noise. The railway concepts require less rigid systems in railway tracks. However, rigid track structure may not be solved with slab track systems. There are number of factors covering the design of ballastless track as follows:

- Absorbing railway track vibrations and noise;

- $\quad$ Supporting layer should have sufficient bearing capacity and elasticity;

- $\quad$ Soil settlement should be expected to have fixed depth; and

- Precaution should be taken to deal with extra settlement.

Turkey also used in railway ballast of railway lines caused many problems will be solved by slab track. In particular, the formation of shifts in the line bearing in the longitudinal and lateral directions due to the nonlinear and plastic behavior of the ballast over time requires regular maintenance. Depending on this situation, maintenance and repair activities create important problems in terms of time and cost in lines that are used extensively such as Ankara-Istanbul and Ankara-Konya High Speed Rail lines. In the same high-speed lines, it is seen that the ballast flies into the air and damages the rail and vehicles. In addition to these situations, it is observed that larger cross-sections are made in the bearing supports due to the heavy load of the ballast in the bridges and viaducts and this increases the construction costs. Also, in tunnel sections, the ballast brings about $30 \mathrm{~cm}$ of additional height and increases construction costs as well. All these reasons have been taken into consideration recently by Turkish State Railways (TCDD), and slab tracks have been started to use in tunnels and bridge-viaducts in the Ankara-Sivas railway line project, which is still under construction.

\section{References}

AASHTO. (1993). AASHTO Guide for Design of Pavements. Washinghton,DC.

Bilow, D., \& Randich, G. (2000). Slab Track Design for Next 100 years. Portland Cement Association.

Esveld , C. (2003). Recent Developments in Slab Track. European Railway Review, 1351-1599.

Esveld, C. (2001). Modern Railway Track 2nd Edition. MRT Production.

Esveld, C., \& Markine, V. (2019, 10 20). Slab Track Design for High Speed Railways. Esveld Consulting Services: http://www.esveld.com/Download/TUD/Bilbao_Esveld_Markine.pdf

Gailiene, I., \& Lasurinavicius, A. (2017). The need and Benefit of Slab Track: case of Lithuania. Gradevinar, 387-396.

German Unity Transport Project 8. "high-speed line Nuremberg - Erfurt - Halle/Leipzig - Berlin". http://www.vde8.de/(05.09.2019)

Hussein, M., \& Hunt, H. (2009). A Numerical Model for Calculating Vibration due to a Harmonic Moving Load on Floating Slab Track with Discontinous Slabs in Underground Railway Tunnel. J.Sound Vibration, 363-374. 
Lichtberger, B. (2011). Track Compendium 2nd edition. Hamburg: Eurail Press.

Lier, S. (1999). The Vibro Acoustic Modelling of Slab Track with Embedded Rails. Journal of Sound and Vibration.

Michas, G. (2012). Slab Track Systems for High-Speed Railways. Sweden: Royal Institute of Technology.

Profillidis , V. (2006). Railway Management and Engineering 3rd edition. Greece: Asgate Publishing Company.

Rail One. (2020, January 10). Rail One Official web site: https://www.railone.com/fileadmin/daten/05-pressemedien/bilddatenbank/070_TS 03 72dpi.jpg

Rail One Slab Track Systems. "Rheda 2000 Ballastless Track System". https://www.railone.com/products-solutions/urbantransit/ballastless-track-systems(14.09.2019).

Railway Technology. "Alice Springs-Darwin Rail Line Construction, Northern Territory, Australia". https://www.railwaytechnology.com/projects/alice/alice4 (14.08.2019).

Railway Technology. “UK's Heriot-Watt University tests slab track system”. https://www.railway-technology.com/news/newsukuniversity-conducts-high-speed-slab-track-testing-5925966/ (21.08.2019).

Rose, J., \& Souleyrette, R. (2015). Asphalt Railway Trackbeds: Recent Designs, Applications and Performances. AREMA.

Samuel Matias; Tecnico Lisboa. "Numerical Modeling and Design of Slab Tracks Comparison with Ballasted Tracks". https://fenix.tecnico.ulisboa.pt/downloadFile/844820067124205/Resumo\%20Alargado.pdf (01.06.2019)

Shiau, Y., Huang , C., Wang, M., \& Lu, L. (2008). New Model of Cement Product-Precast Slab Track for THSR. ISARC, 129140 .

SSF Ingenieure. "Katzenbergtunnel, Feste Fahrbahn”. https://www.ssf-ing.de/projekte/projektdetail/references/Reference/detail/tunnel-offenbau-neubaustrecke-nuernbergingolstadt.html?tx_datamintsssfreferences_pi1\%5BbackParams\%5D=\&cHash=4eb6b179c7f90f7bfc0b1a941a0902a0 (02.10.2019)

Sonneville Slab Track Systems. "System LVT Standard". https://www.sonneville.com/low-vibration-track-lvt/system-lvt$\underline{\text { standard/ }}$ (14.09.2019).

Vossloh Fastening Systems "Type of track". https://www.vossloh.com/en/products-and-solutions/field-ofapplication/fahrbahneigenschaften/ (04.05.2019)

Vossloh Fastening Systems "Rail fastening systems". https://www.vossloh.com/en/products-and solutions/products-atglance/schienenbefestigungssysteme/ (04.05.2019) 